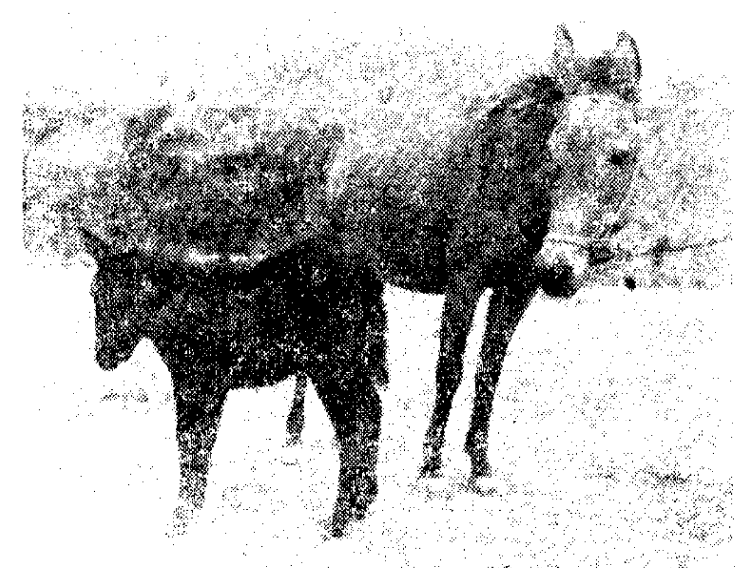

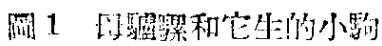

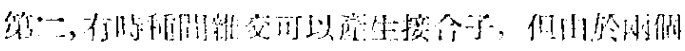

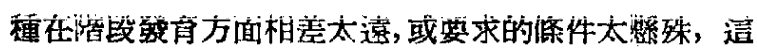
種不協調性造成死亡現象。

第三，有些種間雜交可以童生具有生活能力的雜

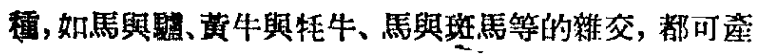

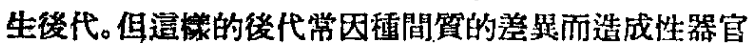

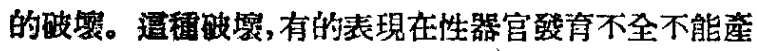
生性細胞,有的表現在性細胞機能缺乏, 有的䒾現在外 生殖器與子宫酸育不完全。邆種不同程度的破壤，可以 在以後的生活過程中, 得到不同程度的饭復, 因之河能

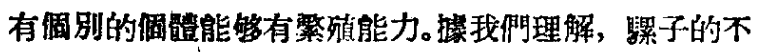

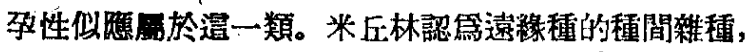

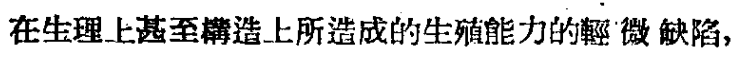

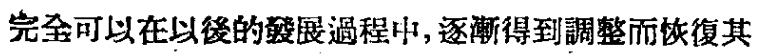
繁殖能力。米丘林曾用實踐證明了他的理論是完全正陮 的。因此我們可以磼信，影子在生長發育過程中，逐潄 調整和饭復其生殖力是完全可能的。

另一方面，根播我們不多的材料，也可以繁助理解

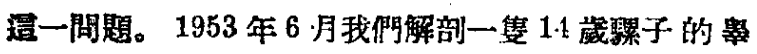

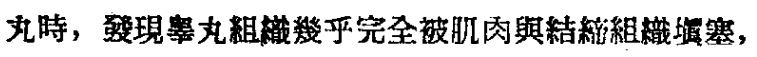
害丸內部不星粉白色而是标褐色。在副器丸內沒有登現

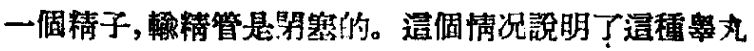

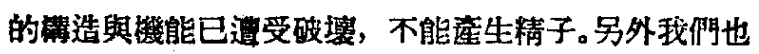

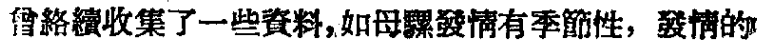

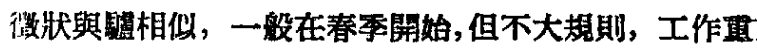

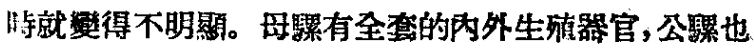
有全套的生殖器官, 並且有性唂。织生殖生理來有, 母

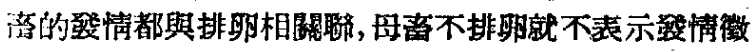

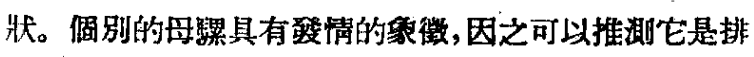

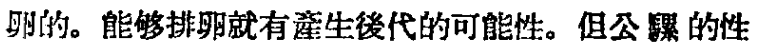

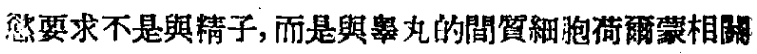

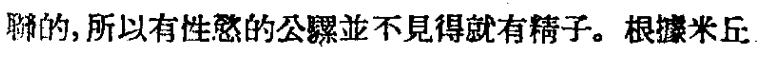
林學說來看, 這種遙丸構造上與機能上的缺陷, 是可以

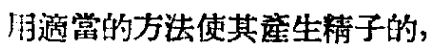

蘇聯先進科學在選方面的成就，給了我們很大的智 洨。例如酉門铪爾牛與牛牛的種間雜種, 已獲得了具有 生殖能力的雄畜,並且現在已由種間雜種育成新的品稙 (中國畜牧整醫新誌 1953 年 1 期 8 面)。

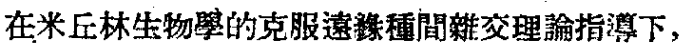

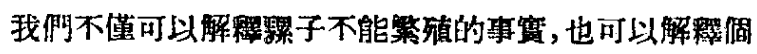
別照子有生㱠能力的原因。鏍子生殖的事窗打破了反動

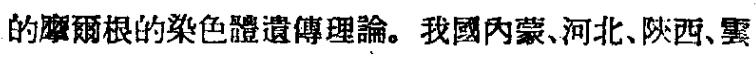
南以及甘肃的酒泉、臨洮等地, 都對繠子生物的事情有 着不少的具體的傳說, 用米丘林生物學的知點來着, 連 些傳說十分可能是可靠的。

米丘林學說的原理使我們得以了解，所有的骡子， 都有饭復其繁殖能力的可能性。饮復過程除了與參與雜

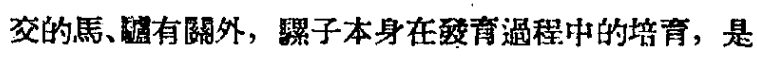
一周重要因素。米丘林指明了親本的選揊與培育是克服

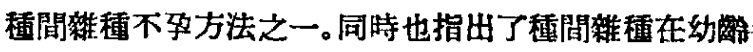

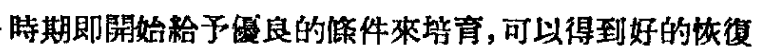
情况, 生物膟育的生活佟件是起决定性作用的因素之

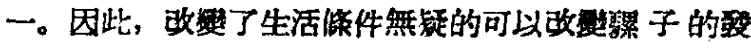
育。

宗恩澤

（西北㽦牧嘼醫盟院）

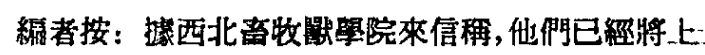

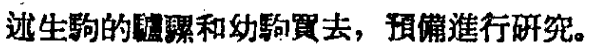

\title{
介紹東北草、炭
}

\section{一 關於草炭的一般情况}

北繶 $40^{\circ}-60^{\circ}$ 互塞帶地區的沼澤濕地中。古代就 生長着許多種植物, 如苔鮮植物以及莎草科、禾本科、木

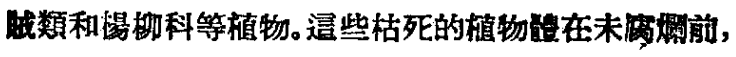

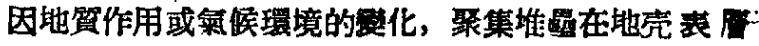
下, 經過數千萬年, 而形成今天遗留在地表下數足的 植尿, 我們就把它叫作草炭層。草炭又因種類不同, 可

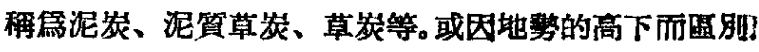

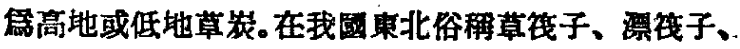

1 月 號

科學通報

- 77 . 
: 荅頭等。

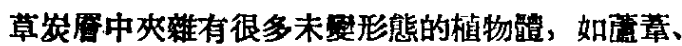

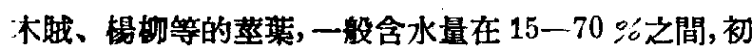

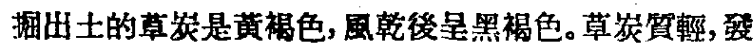

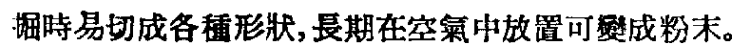

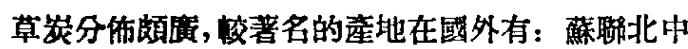
部、䄳恭既、阿拉斯加、加拿大、日本北海道等地。我 回東北地踶埋有大量草炭，北京附近也有發現。

過去，草炭多用作燃料，近來也用作工業原料，製 造活性炭、人造板等, 也有用製顆粒肥料或作保水臍、 苗舍等草等。

\section{二 東北一些地區的草炭埋藏情况}

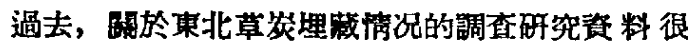

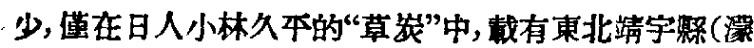

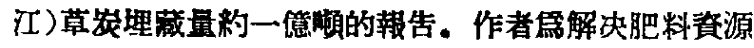
間題曾於 1949-1952 年在吉林省蛟河㲘、㒀德紧、遼

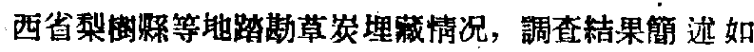
F:

1.遼西省梨樹繁郭家店附近草炭埋藏情况

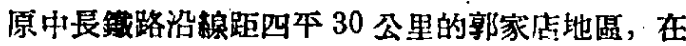
日本帝國主義庴佔封期, 曾罵解决燃料不足, 在郭家店 大城村、滑石山及林大等等處挖掘，利用極孯务的手据

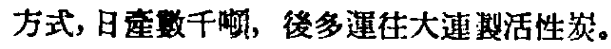

部家店草炭居厚度不一，大域村約 2-- 4 尺，滑石 山地區厚䄪 $5-6$ 尺, 林大满附近較厚, 在地表下 2 尺， 即見厚 $7-9$ 尺的草炭粨。

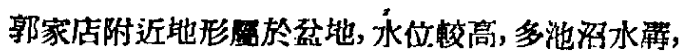

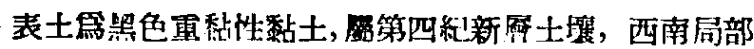

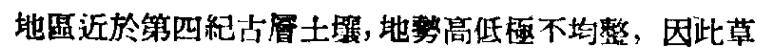
炭層的厚度亦極不均匀。

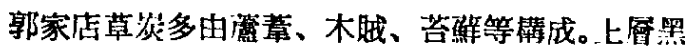

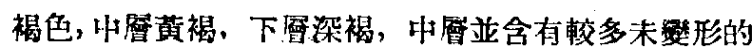

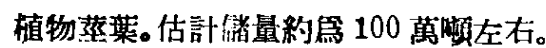

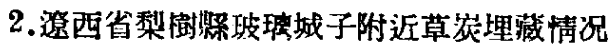

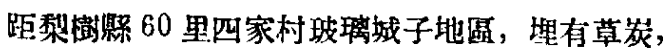

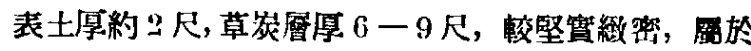

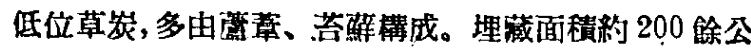
頃, 估計埋藏量約 120 萬覑左右。

3.吉林省胶河踧草炭分㳍情况

蛟河笔拉法及新站附近, 各山存區均有草炭，上㸴 多鹪植物遗體，2尺下埋藏有 3-6 尺疏筑草炭層，俗

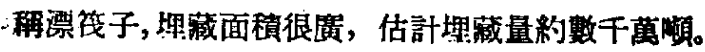

\section{4.吉林省偠德楽草炭分作情况}

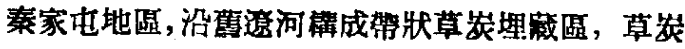

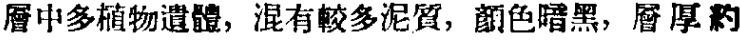
2-3 尺, 分佈面皘約四、五百公頃。當地農瓦有人用 作肥料。

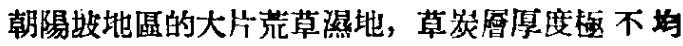

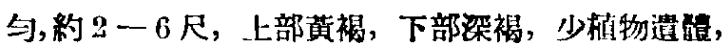

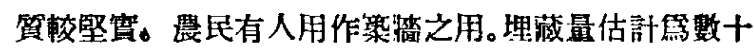
萬湘。

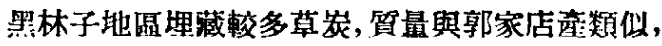

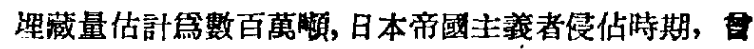
發掘作䉆㸁料。

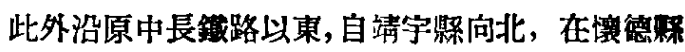

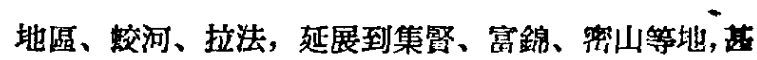

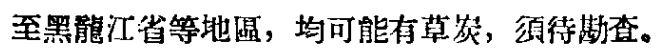

\section{三 東北部分地區草炭利用情况}

東北草炭一向未被很好利用,除在日本帝國主篦佔

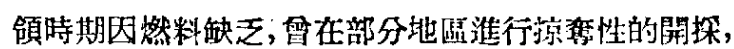
給人民帶來不少災害外，大部仍㙕藏地下。解放後，吉

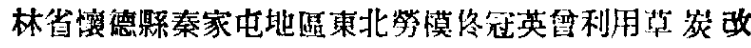

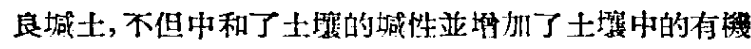

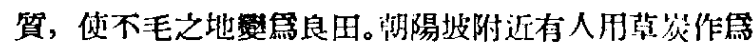

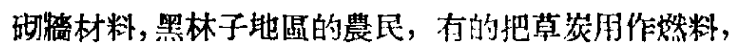

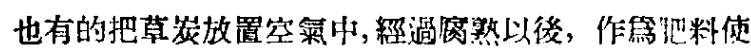
用的。

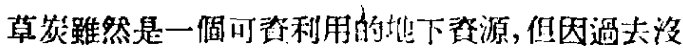

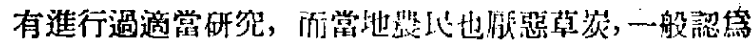

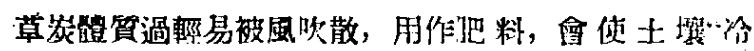

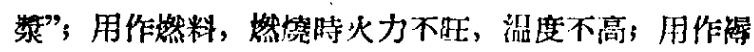

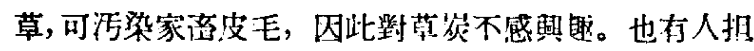
心草炭据出後, 將會把田地躍成水坑, 土地會無法利用,

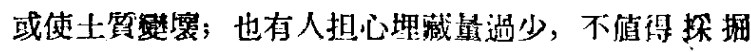
等。

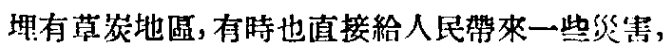
如高位草炭區，因表士過溥，大雨後，人玄有時陷入草炭 㕌, 會發生生命危險; 天旱時期有洔草炭在地下燃燒易 於發生火災（例如拉法地區曾發生地下大火）；在一般 情况下, 埋有草炭厤的區域, 耕地易灌旱淡災害, 居住 地區蚊蟲易於慗殖，都直接間接影響着人民生活。有些 地方的“風土病”, 也可能和草炭厤有閔。

四“對開發與利用草炭方徣的一些意見

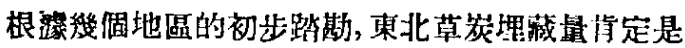
相賞大的, 應該調查並研究利用。

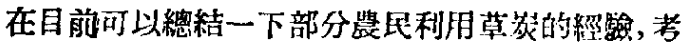

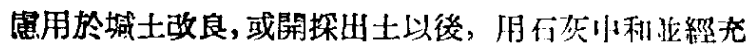


分度等挠，用作肥料。

蘇聯關於顆粒肥料的研觉使肥效大大增加, 今後,

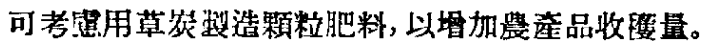

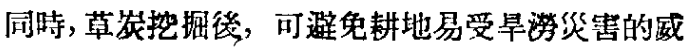

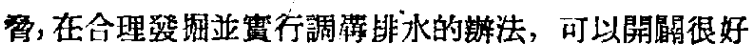
的水田。這㥞根㹉現有條件, 適當利用地下資源, 不但 可解决一部分把料問題, 而且可以改艮土骤, 使它適合

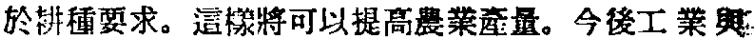
科學的發展, 將使我椚能够更好地利用祖國的一切 源。

我國的科學家、技街工作者們，僬適當注意草炭 源的開發與利用，以增加祖國財䈏資源。

\section{沈 正 舘}

（潘陽農整院）

\section{內服“組織製劑”治療關節炎及消 化性胃瀆湯的初步報告}

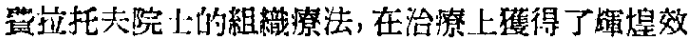
果。密了使組織療法更簡單伦，使病者更易於接受治療 起見, 我們從 1953 年 7 月間開始試用了一種內服窑法。 丝牛年来多次的試用照到有效,各地醫療機關及竍多病

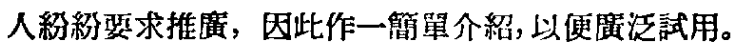

製法:（1)取用健康浐婦新鮮胎盤先以生理照水洗

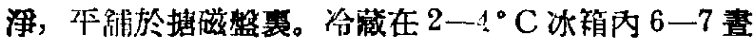

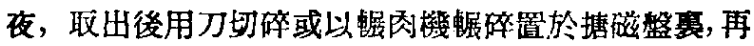
故入 $75^{\circ} \mathrm{C}$ 乾燥箱內 2 書夜, 㤨萼後加高温至 $100^{\circ} \mathrm{C}$, 消毒 2 小時, 整成紬粉。（2）取以上粉劑 1,000 克, 加

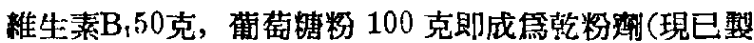
成片鰳)。

服用方法: 郋前後, 一日三次, 每次 2 克, 連日服。

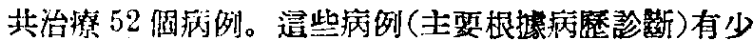

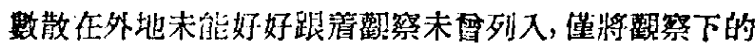
29 调病例叙述如下。

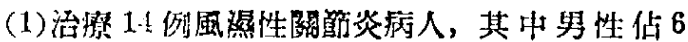
例; 在年紫方面i，18-30 藏者 6 例, 32-62 藏 8 例，病 程第 2-10 年者 7 例， 11 年以.上者 7 例。結果: 14 例 中過去有 5 例作過組織埋藏（胎盤、羊脾）無甚效果。

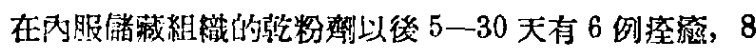
例娍輜。酸察日數 $20-65$ 天。

在病徽方面，一般在內服三天後即感關節虎酸学減

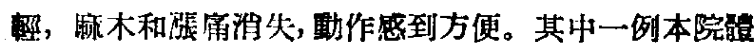

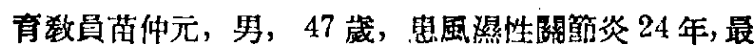

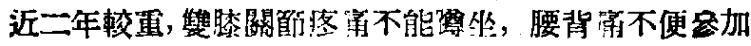
運動，經內服組樴製㓡 5 天後自筧已無薄苦，能致加任 何通動。另一病例本院張志如，女，32藏，自幼年即患

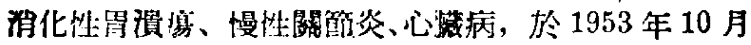

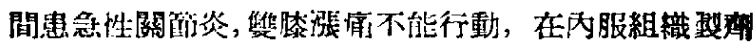

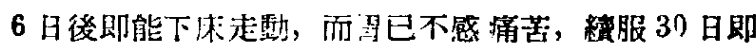

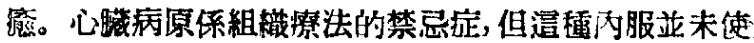
患者有不良反應。

（2）治療 15 例消化性胃㵋痛病人，男性 11 例，年

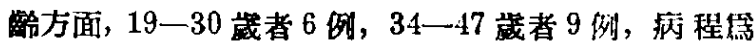
$1-5$ 年 8 例，6-16 年 7 例。15 例中在過去有 6 例作 過組樴埋藏(胎盤、羊脾) 2 -5次無甚效果。在內服組

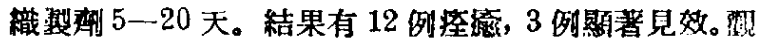
察日數 25-92天。

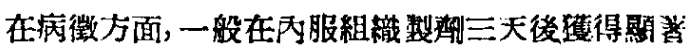

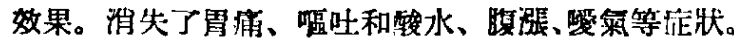

以上二種病人服後均感食烈增加, 洞化力强, 30 天 後體画增加 2-1 磅, 睡眠好, 倩神愉快身體有力, 沒 有感㹂不良反鹤的。

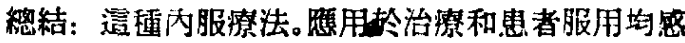
方便，慜備简便且可保持長久不尉，因此可以節省人力 物力的消耗，便於推展使用。對於其他有關組織潦法通

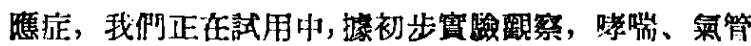

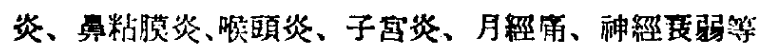
定都有效。

$$
\text { 王思 恭 }
$$

編者按：儖用組織療法，我國一般是用植入法和注

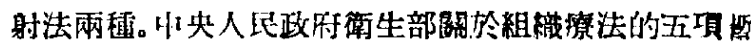
行規定（1951年10月12日）也只規定了植入法、注䑾法

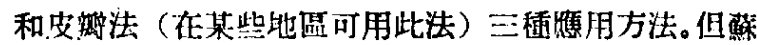

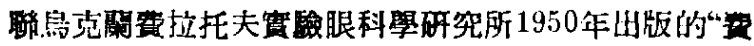

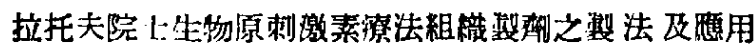
法指留”赛曾經詳細地列寒了內服和外用的方法。內报

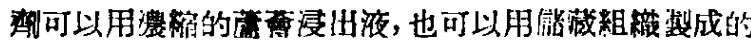
乾粉臍, 外用方面可以用受出液来滴眼、含濑, 或是用;

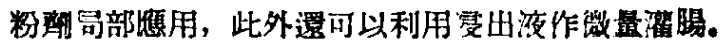
1 月號
一科學 通報 